\title{
DISJUNÇÕES NA APLICAÇÃO DA MEDIDA DE PROTEÇÃO POR ACOLHIMENTO INSTITUCIONAL PARA ADOLESCENTES EM CONFLITO COM A LEI: diálogos multidisciplinares ${ }^{1} / /$ Christopher Rodrigues Anunciação ${ }^{2}$ e Mário Luis Villarruel da Silva ${ }^{3}$
}

\author{
Palavras-chave \\ psicanálise / linguagem / punitivism / direito

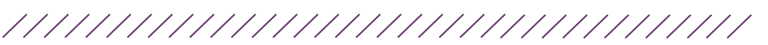

\section{Resumo}

O Estatuto da Criança e do Adolescente, ECA, estabelece medidas de proteção aplicáveis diante de violações dos direitos de crianças e adolescentes, tais como o acolhimento institucional, bem como medidas socioeducativas aplicáveis a adolescentes em conflito com a lei, como a internação. A bibliografia sobre institucionalização de crianças e adolescentes no Brasil aponta uma oscilação entre "criança abandonada" e "menor delinquente", que se materializa, hoje, nos casos em que egressos de internação por ato infracional necessitam da medida de proteção de acolhimento institucional e são submetidos a uma "errância": sucessivas transferências de instituições de acolhimento sob justificativas diversas. Apesar das mudanças legais nos direitos de crianças e adolescentes, a delinquência ainda figura como elemento de exclusão de diversos adolescentes das possibilidades de medidas de proteção, um cenário anacrônico em concurso de direitos, pois o ECA acaba figurando como extensão do código penal. Este trabalho problematiza a condição política desses jovens quando, em sua errância por diversas instituições de acolhimento institucional, são excluídos do Sistema de Garantia de Direitos, aproximando-os do homo sacer de Giorgio Agamben, pois nesses casos suspende-se a ordem jurídica para funcionar um dispositivo que parece autorizar a desproteção à vida do adolescente considerado delinquente. Para isso, apresentamos dados provenientes da observação etnográfica durante discussões de casos de transferência de adolescentes em instituiç̃̃es de acolhimento, de cuja história pregressa constava internação por medida socioeducativa. Estas notas são eminentemente multidisciplinares, advindas do trabalho realizado in loco, considerando em especial diálogos entre a psicanálise, a antropologia do direito e a sociologia da punição.

\footnotetext{
10 presente artigo é uma versão revisada do trabalho apresentado no V ENADIR - Encontro Nacional de Antropologia do Direito (2017). GT.10 - Justiça juvenil, adolescentes em conflito com a lei e instituições de internamento para jovens.

2 Mestrando em Psicologia pela USP: christopherrodrigues.a@gmail.com 3 Doutorando em Psicologia pela USP. Docente da Universidade Federal do Acre - UFAC: mariovillarruel@usp.br

167 


\section{DISJUNCTION ON THE PLACEMENT PROTECTIVE MEASURE'S FOR OFFENDER TEENAGERS: multidisciplinary dialogues // Christopher Rodrigues Anunciação and Mário Luis Villarruel da Silva}

\author{
Keywords \\ Psychoanalysis / language / punitivism / law
}

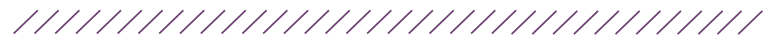

\begin{abstract}
The Estatuto da Criança e do Adolescente [Child and Teenager's Statute] establishes what are the applicable protective measures in situations of children and teenagers' rights violation; as well teenagers' juvenile delinquency programs in conflict with the law, reporting between them, the institutional refuge, in the first case, and the committal, in the second one. The bibliography about children and teenagers' institutionalization in Brazil aims an oscillation between "forlorn infant" and the "juvenile offender", that materializes, now a days, in cases that committal egression by infractional act needs the protection measure of institutional refuge and are undergone an "wandering", undergoing successive host institution transfers under many justifications. This reflection shows us how, instead of important legal changes in children and teenagers rights, the delinquency is, for plenty teenagers, an exclusion element of protection measures, an anachronistic situation treating of rights, doing ECA as an extension of criminal code. In this sphere, this project aims to discuss the political conditions these youngers are going straight, when the wandering by many refuges institutes eventually excludes them to the Rights Assurance System, becoming next to homo sacer by Giorgio Agamben, suspending the legal order, in this kind of case, to make work a system that seems to allow to teenagers treated as delinquents, life's defenselessness. For that, we are going to present ethnographic data, provided by observation during teenagers' transference cases in institutional refuges discusses - that were previously checked by socio-educative measure. The notes presented here are multidimensional, a work realized in loco, considering specially, theorical and methodologic dialogues between psychoanalysis, laws anthropology and punishment sociology.
\end{abstract}


O presente trabalho surge do anseio de comunhão de olhares multidisciplinares convergentes entre o Núcleo de Antropologia do Direito (NADIR) e o Laboratório de Psicanálise e Sociedade (PSOPOL), ambos da Universidade de São Paulo - USP. Nesses espaços, debatem-se problemáticas de diferentes sujeitos e atores sociais que se encontram marginalizados e excluídos pela sua condição política no laço social, como refugiados, migrantes, mulheres vítimas de violência, crianças e adolescentes institucionalizados, entre outros. Elegemos, aqui, debater de forma interdisciplinar, entre os saberes da sociologia, do direito e da psicanálise, essa condição experimentada por adolescentes que oscilam entre o acolhimento institucional e as medidas socioeducativas, ambas previstas no Estatuto da Criança e do Adolescente, ECA (1990).

Cabe explicar, de antemão, a diferença entre essas medidas aplicáveis a crianças e adolescentes no Brasil, para que se possa introduzir seu entrelaçamento histórico e social. A medida de acolhimento institucional está prevista no artigo 101 do ECA como uma das medidas possíveis para os casos de violação de direitos contra crianças e adolescentes, aplicáveis nos casos de maior risco e nos quais os vínculos familiares e comunitários se encontram rompidos. É descrita como uma medida "provisória e excepcional" e não deve durar mais do que dois anos (Brasil, 2016). Já as medidas socioeducativas dispostas no ECA (Art. 112) são aplicáveis nos casos de infrações cometidas por adolescentes, entendidos, conforme o mesmo estatuto, como indivíduos que têm entre 12 anos e 18 anos incompletos. Figura, entre essas medidas, a internação em instituição socioeducativa, atualmente a cargo da fundação CASA (Centro de Atendimento Socioeducativo e Assistencial) (Brasil, 2016, p. 116).

Vale lembrar que o mesmo artigo dispõe de outras medidas aplicáveis ao adolescente que cometeu ato infracional, sendo elas: I - Advertência; II - Obrigação de reparar o dano; III - Prestação de serviço à comunidade; IV - Liberdade assistida; V - Inserção em regime de semiliberdade; VI - Internação em estabelecimento educacional. Nesta análise, deter-nos-emos nas medidas de internação, problematizando também a aparente predileção por elas como tática de encarceramento da população empobrecida.
Essa diferença legal disposta no ECA entre a medida de acolhimento institucional e a medida de internação para adolescentes infratores traz uma novidade na compreensão do atendimento socioassistencial à criança e ao adolescente no Brasil, uma vez que, estudos sobre a história social da infância e da adolescência no país demonstram facilmente como a delinquência sempre figurou como categoria e como condição para a institucionalização (Rizzini \& Rizzini, 2004; Marcílio, 2003).

A pesquisa bibliográfica indicou que a preocupação com a institucionalização de crianças e adolescentes no Brasil emerge desde o Brasil Colônia, fundamentalmente com o modelo da roda dos expostos, uma roda giratória onde uma criança era depositada para ser acolhida por certas instituições, em sua maioria de caráter religioso, garantindo o anonimato do depositante (Alvarez, Schritzmeyer, Salla, Paula \& Cukierkorn, 2009; Rizzini \& Rizzini, 2004; Marcílio, 2003).

Somente no final do século XVIII, com o advento da medicina higienista e de práticas sanitaristas é que esse modelo foi posto em xeque, principalmente pela alta mortalidade de crianças nessas instituições, conforme indicam Alvarez et al. (2009) e Marcílio (2003). Entretanto, o primeiro autor nos esclarece que a assistência à infância e adolescência no Brasil sempre esteve muito mais ligada a um ordenamento público e a uma judicialização da infância empobrecida do que vinculada a questões de cidadania.

Essa mudança, portanto, tira essa problemática das instituições privadas que prestavam auxílio à infância desvalida, tornando-a uma questão de Estado. Os objetivos desse movimento estavam diretamente ligados à gestão do problema social e à preocupação com a delinquência juvenil e ao aumento da criminalidade precoce (Alvarez et al., 2009).

A crescente preocupação com a delinquência desses jovens abandonados, oriundos dos estratos sociais mais pobres, cria uma intensa pressão sobre o Estado para a formulação de uma política de assistência à infância, o que desemboca no período menorista da República, como nomeiam as autoras Rizzini e Rizzini (2004).

Esse complexo período tem como escopo fundamental a categoria menor - menor abandonado e 
menor infrator - que tratou de tomar crianças e adolescentes empobrecidos como possíveis delinquentes passíveis de esquadrinhamento e ordenamento pelos saberes médico, jurídico, político, pedagógico e quaisquer outros discursos que pudessem categorizar e conter o mal-estar que advinha da presença desses jovens nas ruas, principalmente das capitais do Rio de Janeiro e de São Paulo. (Rizzini \& Rizzini, 2004; Alvarez et al., 2009).

O período menorista marca regiamente a institucionalização de crianças e adolescentes no Brasil, tanto pelo abandono, quanto pela delinquência. Na verdade, a criança abandonada, empobrecida, preta, era um possível delinquente e, portanto, deveria ser submetida ao mesmo formato de instituição. Isso produz uma superinstitucionalização desses menores, valendo citar Alvarez et al. (2009):

Uma institucionalização muito mais ampla do que a das antigas formas (como a dos expostos) alcança todos os menores em estado ou em perigo de abandono, aumenta efetivamente a clientela para todo o contingente de crianças das classes pobres e, virtualmente, para todas as crianças da sociedade. Uma institucionalização que tem em seu horizonte, não apenas assistir gratuitamente os desafortunados, mas, sobretudo, combater a delinquência, fruto do abandono, e criar, assim, cidadãos saudáveis, tanto moral como fisicamente. (p. 9)

Para esses autores, o Código de Menores de 1927 é o responsável por cristalizar a figura do menor e apresenta a delinquência como condição subjacente ao infante abandonado. Essa categoria figura nas políticas de assistência à infância e, posteriormente, na criação do Serviço de Assistência ao Menor (SAM) em 1941, seguindo até a criação da Fundação Nacional de Bem-estar do Menor (FUNABEM) em 1973 e só se extinguindo do âmbito legal em 1990 com a promulgação do Estatuto da Criança e do Adolescente, o ECA.

Neste Estatuto se insere a doutrina da proteção integral para a assistência à criança e ao adolescente, em oposição à política menorista. Prevista pela constituição de 1988, essa doutrina postula que, por se tratar de seres em desenvolvimento, crianças e adolescentes merecem atenção especial e diferenciada, visan- do principalmente, ao cuidado integral através da proteção social e material desses indivíduos (Costa, Penso, Olivier Sudbrack \& Jacobina, 2011).

Ainda que represente um importante e inegável avanço na política de assistência à infância e à adolescência no Brasil, o ECA vem sendo criticado por diversos setores da sociedade por seu caráter aparentemente liberal com os adolescentes infratores. Alvarez et al. (2009) indicam que, entre 1993 e 2004, foram apresentadas mais de 20 Propostas de Emenda Constitucional (PEC) ao Estatuto, propondo a redução da maioridade penal de 18 anos para 16 ou até 14 anos de idade.

O ranço da delinquência sobre os jovens no Brasil leva a opinião pública - por diferentes influências midiáticas -, além de setores reacionários e conservadores, a quererem sustentar a punibilidade como a única forma possível de tratamento de adolescentes no país. Ainda que tenhamos algumas das mais rígidas medidas de internação entre diversos países, ainda existe a defesa de modelos mais penalizantes e carcerários voltados aos jovens.

Interessante observar que, entre 1904 e 1906, a principal razão de institucionalização de adolescentes no Brasil era o crime de desordem (40,5\%). Entre 1976 e 1978, 74,4\% das prisões eram por roubo ou furto, segundo a pesquisa de Alvarez et al. (2009). Em um estudo do IPEA, em 2013 a principal causa de internação de adolescentes infratores foi o roubo $(39,9 \%)$ seguido de tráfico (23,55\%). Crimes violentos, como latrocínio, representaram 1,93\% dessas internações, o que contradiz a propaganda de redução da maioridade penal que insiste em alardear que os adolescentes cometem crimes cada vez mais violentos.

Ainda sobre o perfil do adolescente infrator, a pesquisa mais recente a que tivemos acesso é a do IPEA com o Ministério da Justiça (2003), a qual aponta que dos adolescentes internados, 60\% eram negros, 51\% não frequentavam a escola e $66 \%$ viviam em famílias extremamente pobres (Silva \& Oliveira, 2015).

Como explicitam Costa et al. (2011), é preciso considerar que o adolescente infrator no Brasil é também aquele que foi pouco assistido pelas políticas públicas de proteção à infância. São, em sua maioria, 
adolescentes que tiveram infâncias empobrecidas, marcadas pela violação de direitos e que encontram, principalmente no tráfico de drogas, uma via de acesso a bens de consumo propagandeados pelo sistema capitalista (Costa et al., 2011).

No contexto dessa discussão entre garantias de direitos de crianças e adolescentes e atos infracionais por eles cometidos se inserem as nossas observações, extraídas da prática de um dos pesquisadores que esteve inserido como psicólogo e coordenador em diferentes Serviços de Acolhimento Institucional para crianças e adolescentes na cidade de São Paulo. Essas instituições são aquelas que recebem crianças e adolescentes que tiveram seus direitos fundamentais violados e seus vínculos rompidos pelas mais diversas violências, ocasionando a sua institucionalização em abrigos com vistas à proteção e ao bem-estar.

Entre as mais diversas histórias de crianças e adolescentes acolhidas nessas instituições, deter-nos-emos em adolescentes advindos de um longo período de institucionalização em diversos abrigos, desde a infância, e que, após cometerem ato infracional e serem internados na Fundação CASA, encontravam grandes dificuldades para permanecer acolhidos nos abrigos.

Ainda que o ECA preconize que a medida de acolhimento institucional não deva ultrapassar dois anos, muitos acolhidos, devido a condições sociais e materiais diversas, passam toda a infância e a adolescência institucionalizados. Dentre esses indivíduos, foi possível observar que alguns ingressavam na prática de delitos, principalmente no tráfico de drogas, logo no início da adolescência, o que não nos oferece material para afirmar se há predominância desse perfil de jovens egressos do acolhimento institucional nas medidas de internação, muito menos é nosso objetivo, aqui, apresentar dados estatísticos ou quantitativos.

O que nos interessa é analisar singularmente a condição política experimentada por adolescentes com quem tivemos contato, quando egressos de medidas de internação se vêem impossibilitados de retornar à família e precisam retornar às instituições de acolhimento institucional.

Os Serviços de Acolhimento Institucional para Crian- ças e Adolescentes (SAICAs) são as instituições que substituem os antigos orfanatos. Organizados conforme a Política Nacional de Assistência Social (PNAS) e a Normativa Operacional Básica do Sistema Único de Assistência Social (NOB-SUAS), devem acolher no máximo 20 crianças e adolescentes, entre 0 e 17 anos e 11 meses, sendo que não deve haver especificidades, como casas para atender apenas crianças portadoras de HIV/AIDS, por exemplo.

Assim sendo, conforme as portarias supracitadas relativas aos SAICAs, não cabe ao serviço selecionar a demanda, mas acolher quem for enviado pelo poder judiciário ou diretamente pelos conselhos tutelares (Brasil, 2005; Brasil, 2006).

Em meio a tantas dificuldades enfrentadas pelos serviços, como $\mathrm{RH}$ reduzido, cortes de verbas, minimização de repasses e doações ${ }^{4}$, entre outros, muitas instituições tentam "negociar" para não receberem adolescentes, muito menos adolescentes aqueles que tenham histórico de internação, contrariando a legislação. Dessa forma, outras instituições ficam marcadas apenas pela presença de adolescentes, ferindo a lógica que constrói esses Serviços como política pública universal.

Nesse contexto, foi possível atuar em uma instituição marcada pela presença de adolescentes. Desde que assumimos a coordenação da instituição, recebemos muitos pêsames de diversos atores das políticas públicas por considerarem aqueles adolescentes "insolúveis" e ser impossível trabalhar ali. Salvo alguns poucos que conheciam o trabalho e nos ajudavam na tentativa de construir uma estratégia de intervenção, majoritariamente éramos desestimulados a insistir no atendimento daqueles adolescentes.

Juliana Vinuto (2014) observa, nesse sentido, que costuma partir dos próprios servidores a criação de categorias de designação e o consequentemente tratamento dispensado a esses jovens. Em seu trabalho,

4 Na Cidade de São Paulo, conforme Raio-X da Secretaria Municipal de Desenvolvimento Social de 2015, todos os serviços de acolhimento institucional da cidade eram conveniados à prefeitura em parcerias público-privadas com Entidades Sociais e Organizações Não-Governamentais (ONGs), mantendo-se, desse modo, através de doações e de repasses governamentais. 
ela percebeu uma dualidade entre "recuperáveis" (que demonstrariam maior adesão aos propósitos da medida socioeducativa) e "estruturados" (estabelecidos no crime). E tais formas de tratamento passam também a ser formas de acompanhamento, com caráter policialesco.

\section{Conforme observamos:}

O que marca o trabalho da pesquisadora é o valor de como a construção de sentido dos funcionários nessa linha de percepção acarreta em influências decisivas na vida do jovem, tendo em vista que essa adoção terminológica é repassada à escrita de relatórios, endossando seus prontuários e criando categorias de linguagem (a partir da própria morfologia dos termos) que poderão influenciar a decisão legal sobre o processo de reinserção social. (VILLARRUEL-SILVA, 2016, pp. 29-30)

Sobre isso, temos ainda o trabalho de Rosa e Vicentin (2010) que analisam as noções de periculosidade e irrecuperabilidade de adolescentes infratores enredados em discursos psicologizantes, voltados à patologização da infração e a torná-la uma condição intratável. A ótica dos profissionais que lidam com esses adolescentes no dia-a-dia nos mostrava como seria difícil extrapolar essa condição, uma vez que não era oferecida aos adolescentes outra possibilidade de existir que não estivesse atravessada pelo ato infracional.

No caldo de tantas histórias vivenciadas pelo pesquisador psicólogo, elegeremos um fragmento de atuação relativa ao caso de um adolescente acolhido em uma instituição coordenada pelo mesmo pesquisador. Ele será apresentado no formato de vinhetas psicanalíticas, ou seja, excertos de escutas e atendimentos oferecidos no interior dessas instituições.

$V$ itor $^{5}$ foi recebido na instituição após sucessivas transferências nos mais diversos serviços de acolhimento da cidade, depois de sua recente saída da Fundação CASA. O relatório de encaminhamento desse adolescente o descrevia como totalmente irascível,

5 Os nomes oficiais foram suprimidos e substituídos por nomes de identificação fictícia. incapaz de se submeter a regras e quase "impossível" de ser contido na instituição. Segundo o documento, ele fugia das instituições para ser transferido e obter "vantagens" nos serviços em que era recebido6.

Quando o recebemos e o caso foi relatado à equipe, de modo geral parecia ter se instalado um certo "terror" relativo ao adolescente egresso da Fundação CASA. Na mesma semana, corria à boca pequena na instituição que ele teria assassinado um outro adolescente na Fundação. Ora, ele fora internado por causa de latrocínio. No relato do adolescente, sua internação deu-se por envolvimento com tráfico de drogas em seu território de origem.

Sobre isso, o trabalho de Catroli e Rosa (2013) nos faz refletir que essas histórias de violação poderiam ser narradas pelo adolescente, em prol de uma narrativa em que ele pudesse apontar laços sociais marcados pela violência e pela anomia e em que a vida e a morte do próprio adolescente e as de seus pares parecem ser indiferentes ao poder instituído. Assim sendo, a demonstração de uma narrativa fantasmática, encampada por intensa violência, pode garantir determinadas inserções e "sobrevivências" em meio a determinados laços sociais.

Nas conversas com Vitor, ele nos relatou estar institucionalizado desde os seis anos de idade. Segundo suas contas, já teria passado por pelo menos quatorze abrigos. "Ou eram quinze? Eu não lembro direito, tio". Dizia que aos doze anos começou a traficar como "mulinha", levando drogas para o abrigo em que estava acolhido, o que ocasionou sua primeira internação ${ }^{7}$. Desde então, se lembra que foram muitos os abrigos dos quais fugia, ficando em situação de rua e acabando por ser acolhido novamente.

Vitor permaneceu apenas um mês acolhido na instituição, até fugir e ir para outro território. Nesse período, em todas as instituições que tentávamos inseri-lo,

6 Todas as informações sobre o caso foram coletadas através de um "diário de bordo" redigido pelo pesquisador entre os anos de 2014 e 2016, além de dados documentais oriundos de relatórios, ofícios e consulta processual.

7 Não é possível afirmar que havia mais de uma internação devido a inconsistências no seu relato, nos documentos apresentados e pelo curto tempo em que ele permaneceu acolhido nessa instituição. 
como escola ou formação profissionalizante, recebíamos severas negativas. Para matriculá-lo na escola, foi preciso acionar o Ministério Público, pois a direção recusava-se a receber um adolescente "com esse histórico". Ou então ouvíamos que "qualquer passo desse menino na escola será informado ao juiz".

Até a fuga de Vitor da instituição, houve duas situações paradigmáticas em que nos deteremos nesta análise. Na primeira, estávamos com ele andando pelo bairro. Era uma das formas de mantê-lo calmo e sem o desejo de deixar a instituição, pois segundo ele era "insuportável" permanecer ali. Numa dessas caminhadas, com mais dois adolescentes acolhidos, entramos em uma loja quando um carro de polícia foi lançado na calçada. Dois policiais desceram, com as armas em punho, enquanto um outro tentava nos afastar dos adolescentes que, nessa altura, já estavam com as mãos no muro e pernas abertas ouvindo os gritos dos policiais.

Em meio ao horror dessa cena, dei os documentos dos adolescentes e informei que eram acolhidos da instituição. Ainda com descrédito, os policiais interromperam a ação dizendo "cuidado moleque, a gente se vê". Dias depois, chegando à instituição deparamo-nos com uma aglomeração de pessoas, um carro da polícia e, na cena, Vitor estava encostado em um muro, com as pernas abertas. Três policiais o abordavam. Quando fui até a cena, descubri que um vizinho da instituição acionara a polícia porque ele estava "fumando maconha" próximo à sua residência. O policial nos chamou "de canto" e pediu para que esquecêssemos o que estava acontecendo, pois ele poderia pegar o adolescente, colocá-lo no carro e "dar um jeito". "Posso dar uma surra, ou se você quiser...".

Apresentei novamente seus documentos e me dispus a levá-lo de volta, por ser seu responsável legal. Dias depois, quando Vitor se evadiu da instituição, durante uma madrugada, ainda pude ouvir ressonâncias da fala do policial em vozes de outros profissionais. Desde então, não tivemos outras notícias do adolescente.

É importante esclarecer que esse relato não visa denunciar, muito menos personificar o mal presente em determinadas instituições em detrimento de outras, mas demonstrar como determinadas práticas discur- sivas se sustentam a despeito da garantia de direitos e reverberam nas suas mais variadas formas em diferentes atores sociais.

A condição política de Vitor, nessa cena, exprime para nós o que Agamben (2007), em sua obra "O poder soberano e a vida nua", apresenta como a do homo sacer. Essa figura, resgatada pelo autor do direito romano arcaico, quer dizer aquele que é insacrificável e matável, ou seja, está contido na contraditória e problemática distinção do que pode ser "matado por qualquer um", mas não pode ser imolado nas condições prescritas de sacralidade.

A partir dessa noção, Agamben (2007) discute a atualidade do homo sacer como uma condição política daquele que tem uma vida insignificante e, por isso, pode ser "matado" por qualquer um. Segundo o autor, o termo sacer indica "uma vida absolutamente matável, objeto de uma violência que excede tanto a esfera do direito quanto a do sacrifício" (Agamben, 2007, p. 93).

O autor ainda explicita que a condição de sacer não é exclusiva, mas qualquer um pode nela recair e que, nessa condição, a vida depende da decisão soberana.

Soberano e homo sacer apresentam duas figuras simétricas, que têm a mesma estrutura e são correlatas, no sentido de que soberano é aquele em relação ao qual todos os homens são potencialmente homines sacri e homo sacer é aquele em relação ao qual todos os homens agem como soberanos. (Aganben, 2007, p. 92)

O relato sobre Vitor nos parece uma expressão vívida de alguém que, na condição de sacer, experimentou a decisão do soberano, daquele que tem, segundo Foucault, citado por Agamben (2007) o direito de vida e de morte. Nesse caso, o direito de vida e de morte do soberano coloca em suspensão a lógica formal do direito sobre a vida e sobre a morte. O corpo do homo sacer é um corpo “matável”, um corpo desprezável.

No jogo de tensões entre instituições e seus discursos é que a vida de adolescentes como Vitor é lançada, expressa na fala de quem nos disse "decida você, posso dar um jeito nele". Ou seja, essas vidas, que não valem nada, são corpos que pesam politicamente como 
corpos que podem ser destruídos em nome da ordem social. Nos relatos que ouvimos desses adolescentes é sabido que o corpo do jovem negro, pobre, de periferia é aquele que parece poder ser descartado através da decisão soberana.

O lugar do soberano, portanto, vai se materializando cada vez que se lança mão dessa lógica que alija esses adolescentes dos seus direitos fundamentais. 0 que nos parece é que, após tantas violações sofridas, seguidas de uma vida de errância pela institucionalização e marcada pelo rompimento no lugar de haver vínculos, as instituições vão tomando esses adolescentes como seres matáveis. "Hoje morre um, amanhã tem mais dez", são narrativas comuns no cotidiano desse tipo de trabalho.

Todavia, no momento em que Vitor é nomeado, mostramos seus documentos, dizemos de onde veio e o levamos de volta para a instituição, esperamos ter produzido uma fissura nesse discurso, um espaço vazio, recém-criado, por onde o sujeito atravesse sua condição de sacer. Dessa forma, a quebra da ordem discursiva dá início à quebra do status social de abjeção relegada a essas pessoas, não perdendo de vista o quão importante se faz questionar a dinâmica da linguagem produtora de sujeitos e reguladora de condutas.

HIIIIIIIIIIIIIIIIIIIIIIIIIIIIIIIIII

\section{Referências}

Agamben, G. (2007). Homo sacer: o poder soberano e a vida nua. Belo Horizonte: Ed. UFMG.

Alvarez, M. C., Schritzmeyer, A. L. P., Salla, F. A., Paula, L. \& Cukierkorn, M. M. O. B. (2009). Adolescentes em conflito com a lei: pastas e prontuários do "Complexo do Tatuapé" (São Paulo/ SP, 1990 - 2006). Rev. Bras. Adolescência e conflitualidade, 1(1), 10-31. Recuperado em 10 de junho de 2018, de http://nevusp.org/wp-content/uploads/2015/01/down232.pdf

Brasil, Ministério do Desenvolvimento Social e Combate a Fome. (2005). Política Nacional de Assistência Social. Brasília, DF, 178p.

Brasil, Ministério do Desenvolvimento Social e Combate a Fome. (2006). Norma Operacional Básica de Recursos Humanos do SUAS NOB-RH/SUAS. Brasília, DF, 45p.

Brasil. (2016). Estatuto da Criança e do adolescente: Lei n.8069, de 13 de julho de 1990, e legislação correlata. São Paulo: Secretaria Municipal de Direitos Humanos e Cidadania.

Catroli, V. S. C. \& Rosa, M. D. (2013). O laço social na adolescência: a violência como ficção de uma vida desqualificada. Estilos da clínica, São Paulo, 18(2), 297-317. Recuperado em 10 de junho de 2018, de https://www.revistas.usp.br/estic/article/view/79850/83807

Costa, L.F., Penso, M. A., Olivier Sudbrack, M. F. \& Jacobina, O. M. P. (2011). Adolescente em conflito com a lei: o relatório psicossocial como ferramenta para promoção do desenvolvimento. Psicologia em Estudo, Maringá, 16(3), 379-387. Recuperado em 02 de agosto de 2017, de http://www.scielo. br/pdf/pe/v16n3/v16n3a05.pdf

Marcilio, M. L. (2003). A roda dos expostos e a criança abandonada na História do Brasil. In FREITAS, M. C. de (Org.). História social da infância no Brasil. São Paulo: Cortez. 5. Ed.

Rizzini, I \& Rizzini, I. (2004). A institucionalização de crianças no Brasil: percurso histórico e desafios do presente. Rio de Janeiro: Ed. PUC-Rio.

Rosa, M. D. \& Vincentin, M. C. (2010). Os Intratáveis: o exílio do adolescente do laço social pelas noções de periculosidade e irrecuperalidade. Psicologia Política, 10(9), 107-124.

Villarruel-Silva, M. L. (2016). Direito, discurso e poder. Niterói/RJ: PPGSD-UFF. 
Vinuto, J. (2014). Entre o 'Recuperável' e o 'Estruturado': classificações dos funcionários de medida socioeducativa de internação acerca do adolescente em conflito com a lei. Dissertação de Mestrado, Faculdade de Filosofia, Letras e Ciências Humanas da Universidade de São Paulo, São Paulo.

Silva, E. R. A \& Oliveira, R. M. (2015). O Adolescente em Conflito com a Lei e o Debate sobre a Redução da Maioridade Penal: esclarecimentos necessários (Nota técnica do Instituto de Pesquisa Econômica Aplicada - IPEA). Brasília: Instituto de Pesquisas em Economia Aplicada. 